OPEN ACCESS

Edited and Reviewed by: Claire Kremen,

University of British Columbia, Canada

*Correspondence:

Mariana Benítez

mbenitez@iecologia.unam.mx

Specialty section:

This article was submitted to Agroecology and Ecosystem Services, a section of the journal

Frontiers in Sustainable Food Systems

Received: 06 December 2021

Accepted: 20 January 2022

Published: 11 February 2022

Citation:

Benítez M, Rosell JA and Perfecto I

(2022) Editorial: Mathematical

Modeling and Complex Systems in Agroecology.

Front. Sustain. Food Syst. 6:829551.

doi: 10.3389/fsufs.2022.829551

\section{Editorial: Mathematical Modeling and Complex Systems in Agroecology}

\author{
Mariana Benitez ${ }^{1 *}$, Julieta A. Rosell ${ }^{1}$ and Ivette Perfecto ${ }^{2}$ \\ ${ }^{1}$ Laboratorio Nacional de Ciencias de la Sostenibilidad, Instituto de Ecología, Universidad Nacional Autónoma de México, \\ Mexico City, Mexico, ${ }^{2}$ School for Environment and Sustainability, University of Michigan, Ann Arbor, MI, United States
}

Keywords: modeling, complex systems, agroecology, theory, agri-food, social movements, peasant agriculture

\author{
Editorial on the Research Topic
}

\section{Mathematical Modeling and Complex Systems in Agroecology}

The ecologist, mathematician, and activist Richard Levins once said that modeling and simulating from a complex systems perspective had made important advances at integrating different interacting factors, and illustrated this with an example in functional medicine. However, he argued, following on his example around the human body, these modeling efforts often stopped at the skin, as they tended to neglect the socioeconomic and political relationships that largely determine human health and disease (Levins, 2015). A nuanced understanding of diverse socio-ecological processes associated with agroecosystems has certainly been enhanced by theoretical and modeling approaches, including seminal work on competition within polycultures, autonomous pest-control, population and meta-population dynamics, network analyses and peasant balances, among other topics (e.g., Levins, 1969; Stenseth, 1977; Garcia-Barrios, 2003; Perfecto and Vandermeer, 2010; García-Barrios et al., 2011; Woodward and Bohan, 2013; Vandermeer and Perfecto, 2017; McCune et al., 2021). However, we would agree with Levins that, also in this field, it remains a major challenge for complex systems sciences to go beyond the skin.

We believe that developments in the field of mathematical modeling and complex systems should not only continue to integrate diverse interacting variables and scales, but also contribute to the construction of tools for thought (Waddington, 1977). These tools could represent a sort of enriched common sense that allows the study, design, and transformation of agroecosystems from the plot, to the landscapes, to whole agri-food systems. They would allow practitioners in Agroecology, scientists, organized peasants, local promoters, technicians, and others, to be able to recognize the signatures of complexity (Vandermeer and Perfecto, 2017), to distrust magic bullets and to be prepared for abrupt qualitative changes, uncertain or unpredictable phenomena, spontaneous formation of spatial and temporal patterns and properties, and non-linear causation. Such enriched common sense may thus not only enhance Agroecology as a science, but also as a social movement that pursues peasant rights in a changing world (Wezel et al., 2009; UNDROP, 2018).

The Research Topic Mathematical Modeling and Complex Systems in Agroecology contributes with conceptual and technical tools to advance these challenges. On the one hand, it gathers a 
collection of articles that put forward case-studies, models, methods, and approaches that illustrate the potential of mathematical modeling and complex systems in Agroecology, also providing new tools: conceptual, technical and, overall, for thought. On the other hand, this collection also includes articles that, from a complex systems and modeling perspective, also aim at integrating or informing specific sociopolitical issues.

Vandermeer opens this Research Topic with a profound theoretical piece in which he draws from two core themes in Complexity Sciences, namely, spatial pattern formation by reaction diffusion mechanisms (Turing, 1952) and chaos as applied to understanding local decision-making by peasants (Simon, 1957). This synthesis, in which Vandermeer rigorously incorporates the sociopolitical issues surrounding peasant agriculture, puts forward a qualitative approach that may constitute a theoretical foundation for understanding the ecology of peasant Agroecology. Also on the basis of core concepts in Complexity, Ong and Liao make a timely contribution highlighting the importance of theory for understanding and fostering agroecological transitions. Departing from a literature review on transitions that identifies the main social and political factors that have driven food systems into their current crisis, the authors propose to approach production syndromes using critical transition theory. Considering peasant and capitalist production systems as stable state alternatives, Ong and Liao show how their proposed framework can identify factors, mainly social and political, allowing or impeding transitions between production syndromes. Such an approach can thus guide efforts and policy fostering agroecological transitions and ultimately agroecological scaling. Along the lines of approaching agroecological transitions through the lens of critical transition theory, Griffon et al. provide an interesting application of this framework in combination with dynamical systems equations and network analysis. The authors examine the conuco, a millenary traditional farming system that is characterized by high levels of agrobiodiversity and multiple interactions between its components. Building a network of ecological interactions based on scientific and traditional knowledge, the authors compare the network of the conuco with that of corn monocultures. Their theoretical experiments show forcefully that the density of ecological interactions is key for the persistence of the species in the system, a crucial result that highlights the importance of fostering ecological interactions across agrobiodiversity elements in agroecological systems.

As shown by several of the papers within this Research Topic, one of the main tools developed around complexity sciences are networks, which can be fruitfully studied both as static or dynamic entities. Arroyo-Lambaer et al. use well-established network metrics in order to analyze and compare cognitive maps regarding the degradation of agricultural soils across different social sectors in Mexico. Their study includes small farmers, large agricultural producers, members of civil society organizations, and government officials, and highlights common and potentially conflicting aspects among them. But besides developing on previous methods for cognitive-map analysis, this study aims to feedback small-farmers' knowledge of the soil systems, as well as to inform the design of agricultural policies in order to address the longstanding debt toward peasants and agricultural communities that have been left out from the design of agricultural policies and programs in Mexico (CEMDA, 2020). In another contribution, García-Jácome et al. creatively articulate dynamic Boolean networks and agent-based models in order to integrate two decades of socio-ecological research into a model. This approach allows the authors to test different scenarios of community resource management within a protected area in the Yucatan Peninsula, in Mexico. Their results suggest that peasant multiple resource use strategies, including traditional milpa cultivation, are fully compatible with biodiversity conservation within the site. Importantly, milpa cultivation as it used to be practiced in this site has been forbidden de facto due to conservation considerations. This paper thus provides a concrete basis to review such regulations, which along with the sharp tendency toward tourism-oriented specialization, jeopardize food security in the region.

Identifying the complex patterns and processes driving food security could lead to very much needed variables that easily and reliably assess different aspects of food security status. On this line, Barba-Escoto et al. set up to develop a predictive modeling tool of food security, through the use of machine learning techniques. By doing so, the authors identified key factors and interactions associated with food security, which in turn explained a large percentage of the variability documented from an impressive family-oriented survey in Guatemala. Moreover, the authors were able to detect highly non-linear interactions between land availability and other factors driving food security. Revealing such often counterintuitive patterns may certainly contribute to enriching our common sense around food security and inform communitary or governmental decisions aiming to improve food security in the region. On a similar line, Doi et al. evaluated the accuracy of a crop yield prediction system, which integrates a climate prediction and a crop growth model. As a result, the authors found that this prediction system works relatively well for wheat data and points to strategies to improve the system for other crops and for diverse climatic conditions. The authors argue for the use of this type of system in order to provide useful information to large stakeholders, like agribusiness companies and governments. It would be necessary, however, to further reflect on the potential use or impact of such predictive tools in relation to the peasant farmers and organizations that have pushed Agroecology not only as a science, but also as a social movement (Wezel et al., 2009; Giraldo and Rosset, 2018).

Overall, this Research Topic gathers contributions from scientists working on integrative approaches that consider the complexity of agroecosystems, be it through the use of mathematical and computational models or through other conceptual and methodological resources of Complexity Sciences and modern Ecology. It shows the great potential of modeling in: (i) integrating very diverse ecological, social, political factors in a formal framework, (ii) generating general 
understandings of food systems beyond case studies, and (iii) guiding efforts to accelerate agroecological transitions around the world. It indeed provides a panoramic view of the possibilities and perspectives of the research being carried out in these directions, offering approaches that might become instrumental in the generation of a common sense that is congruent with the complex nature of agroecosystems, and that might help complex systems approaches go well-beyond the skin.

\section{AUTHOR CONTRIBUTIONS}

$\mathrm{MB}$ and JR wrote a first draft and all authors carefully read, reviewed, and further edited it. All authors participated in the

\section{REFERENCES}

CEMDA (2020). Otro México es posible. Diálogos para la construcción del Estado pluricultural. Ciudad de México: Centro Mexicano de Derecho Ambiental.

Garcia-Barrios, L. (2003). "Plant-plant interactions in tropical agriculture", in Tropical Agroecosystems, ed J. H. Vandermeer (Boca Raton, FL: CRC Press), 11-58. doi: 10.1201/9781420039887.ch2

García-Barrios, L., García-Barrios, R., Waterman, A., and Cruz-Morales, J. (2011). Social dilemmas and individual/group coordination strategies in a complex rural land-use game. Int. J. Commons. 5, 364-387. doi: 10.18352/ijc.289

Giraldo, O. F., and Rosset, P. M. (2018). Agroecology as a territory in dispute: between institutionality and social movements. J. Peasant Stud. 45, 545-564. doi: 10.1080/03066150.2017.1353496

Levins, R. (1969). Some demographic and genetic consequences of environmental heterogeneity for biological control. Am. Entomol. 15, 237-240. doi: 10.1093/besa/15.3.237

Levins, R. (2015). Una pierna adentro, una pierna afuera. Ciudad de México: CopIt-arXives and EditoraC3.

McCune, N., Luna, Y., Vandermeer, J., and Perfecto, I. (2021). "Cuestiones agrarias y transformaciones agroecológicas”, in Agroecología y Sistemas Complejos: Planteamientos epistémicos, casos de estudio y enfoques metodológicos, eds M. Benítez, T. Rivera-Núñez, and L. García-Barrios (Ciudad de México: CopIt ArXives), 27-50.

Perfecto, I., and Vandermeer, J. (2010). The agroecological matrix as alternative to the land-sparing/agriculture intensification model. Proc. Natl. Acad. Sci. U.S.A. 107, 5786-5791. doi: 10.1073/pnas.0905455107

Simon, H. A. (1957). Models of Man; Social and Rational. Hoboken: Wiley. doi: $10.2307 / 2550441$

Stenseth, N. C. (1977). On the importance of spatio-temporal heterogeneity for the population dynamics of rodents: towards a theoretical foundation of rodent control. Oikos 29, 545-552. doi: 10.2307/3543593 design and edition of the Research Topic being introduced in this Editorial and contributed to the article and approved the submitted version.

\section{ACKNOWLEDGMENTS}

We would like to thank all the authors, reviewers, and editors involved in the preparation of the Research Topic Mathematical Modeling and Complex Systems in Agroecology, which was partly developed during the challenging times of the COVID-19 pandemic. MB was supported by UNAM-DGAPAPAPIIT (IN207819) and CONACyT (217367) and thanks Aimé Rubini for help with formatting the text. IP was supported by NSF (DEB-1853261).

Turing, A. M. (1952). The chemical basis of morphogenesis. Phil. Trans. R. Soc Lond. B 37-72. doi: 10.1098/rstb.1952.0012

UNDROP (2018). UN Declaration on the Rights of Peasants and other People Working in Rural Areas. Available online at: https://digitallibrary.un.org/ record/1650694 (accessed November 25, 2021)

Vandermeer, J., and Perfecto, I. (2017). Ecological Complexity and Agroecology. London: Routledge. doi: 10.4324/9781315313696

Waddington, C. H. (1977). Tools for Thought. St. Albans: Paladin.

Wezel, A., Bellon, S., Dor,é, T., Francis, C., Vallod, D., and David, C. (2009). Agroecology as a science, a movement and a practice. a review. Agron. Sustain. Dev. 29, 503-515. doi: 10.1051/agro/2009004

Woodward, G., and Bohan, D. (2013). Ecological Networks in an Agricultural World. London: Academic Press.

Conflict of Interest: The authors declare that the research was conducted in the absence of any commercial or financial relationships that could be construed as a potential conflict of interest.

Publisher's Note: All claims expressed in this article are solely those of the authors and do not necessarily represent those of their affiliated organizations, or those of the publisher, the editors and the reviewers. Any product that may be evaluated in this article, or claim that may be made by its manufacturer, is not guaranteed or endorsed by the publisher.

Copyright (c) 2022 Benitez, Rosell and Perfecto. This is an open-access article distributed under the terms of the Creative Commons Attribution License (CC BY). The use, distribution or reproduction in other forums is permitted, provided the original author(s) and the copyright owner(s) are credited and that the original publication in this journal is cited, in accordance with accepted academic practice. No use, distribution or reproduction is permitted which does not comply with these terms. 